\title{
Non-alcoholic Fatty Liver Disease: Growing Burden, Adverse Outcomes and Associations
}

\author{
Ramesh Kumar*1 ${ }^{1}$, Rajeev Nayan Priyadarshi ${ }^{2}$ and Utpal Anand ${ }^{3}$ \\ ${ }^{1}$ Department of Gastroenterology, All India Institute of Medical Sciences, Patna, India; ${ }^{2}$ Department of Radiodiagnosis, All India \\ Institute of Medical Sciences, Patna, India; ${ }^{3}$ Department of Surgical Gastroenterology, All India Institute of Medical Sciences,
} Patna, India

\begin{abstract}
Nonalcoholic fatty liver disease (NAFLD) is a systemic disorder with a complex multifactorial pathogenesis and heterogenous clinical manifestations. NAFLD, once believed to be an innocuous condition, has now become the most common cause of chronic liver disease in many countries worldwide. NAFLD is already highly prevalent in the general population, and owing to a rising incidence of obesity and diabetes mellitus, the incidence of NAFLD and its impact on global healthcare are expected to increase in the future. A subset of patients with NAFLD develops progressive liver disease leading to cirrhosis, hepatocellular carcinoma, and liver failure. NAFLD has emerged as one of the leading causes of cirrhosis and hepatocellular carcinoma in recent years. Moreover, HCC can occur in NAFLD even in absence of cirrhosis. Compared with the general population, NAFLD increases the risk of liverrelated, cardiovascular and all-cause mortality. NAFLD is bidirectionally associated with metabolic syndrome. NAFLD increases the risk and contributes to aggravation of the pathophysiology of atherosclerosis, cardiovascular diseases, diabetes mellitus, and chronic kidney disease. In addition, NAFLD is linked to colorectal polyps, polycystic ovarian syndrome, osteoporosis, obstructive sleep apnea, stroke, and various extrahepatic malignancies. Extended resection of steatotic liver is associated with increased risk of liver failure and mortality. There is an increasing trend of NAFLDrelated cirrhosis requiring liver transplantation, and the recurrence of NAFLD in such patients is almost universal. This review discusses the growing burden of NAFLD, its outcomes, and adverse associations with various diseases. Citation of this article: Kumar R, Priyadarshi RN, Anand $U$. Non-alcoholic fatty liver disease: Growing burden, adverse outcomes and associations. J Clin Transl Hepatol 2020;8(1):76-86. doi: $10.14218 /$ JCTH.2019.00051.
\end{abstract}

Keywords: NAFLD; NASH; Metabolic; Outcome; Association.

Abbreviations: $\mathrm{AP}$, acute pancreatitis; $\mathrm{CC}$, cryptogenic cirrhosis; $\mathrm{CI}$, confidence interval; CKD, chronic kidney disease; CVA, cerebrovascular accident; CVD, cardiovascular disease; DM, diabetes mellitus; HCC, hepatocellular carcinoma; HR, hazard ratio; IR, insulin resistance; LT, liver transplantation; MetS, metabolic syndrome; NAFL, nonalcoholic fatty liver; NAFLD, nonalcoholic fatty liver disease; NASH, nonalcoholic steatohepatitis; NHANES, National Health and Nutrition Examination Surveys; OSA, obstructive sleep apnea; OR, odds ratio; PCOS, polycystic ovarian syndrome; SS, simple steatosis; T2DM, type 2 diabetes mellitus. Received: 10 October 2019; Revised: 3 December 2019; Accepted: 9 December 2019

*Correspondence to: Ramesh Kumar, Department of Gastroenterology, All India Institute of Medical Sciences, 4th floor, OPD Block, Patna 801507, India. Tel: +917765803112, E-mail: docrameshkr@gmail.com

\section{Introduction}

Nonalcoholic fatty liver disease (NAFLD) is characterized by accumulation of fat in $\geq 5 \%$ of hepatocytes in the absence of significant alcohol consumption ( $<30 \mathrm{~g} /$ day for men and $<20$ $\mathrm{g} /$ day for women) or secondary causes of hepatic steatosis. ${ }^{1}$ Histologically, the spectrum of NAFLD ranges from simple steatosis (SS) that in some patients can progress to nonalcoholic steatohepatitis (NASH), advanced fibrosis, cirrhosis, and ultimately hepatocellular carcinoma (HCC), and liver failure. NAFLD, once believed to be an innocuous condition, has emerged as the leading cause of chronic liver disease in many countries worldwide. ${ }^{2,3}$ NAFLD is now pandemic worldwide and its prevalence has increased considerably over the last two decades. ${ }^{4-7}$

The changing epidemiology of NAFLD in Asia during the past two decades is well-documented. 4,6,7 NAFLD is strongly associated with metabolic syndrome (MetS), the components of which include hypertension, hyperglycemia, abdominal obesity, and dyslipidemia. ${ }^{8}$ However, NAFLD is not merely a hepatic manifestation of MetS but rather both a consequence as well a predecessor of MetS. Compared with the general population, NAFLD patients are at increased risk of liverrelated, cardiovascular and all-cause mortality. NAFLD has been associated with a large number of extrahepatic conditions, such as type-2 diabetes mellitus (T2DM), atherosclerosis, cardiovascular disease (CVD), chronic kidney disease (CKD), polycystic ovarian syndrome (PCOS), obstructive sleep apnea (OSA), extrahepatic malignancies, etc. ${ }^{9,10}$ Recent data suggest that NAFLD increases the susceptibility and/or worsen outcome of acute pancreatitis (AP), cerebrovascular accident (CVA), and osteoporosis. ${ }^{11-13}$

There is growing trend of patients with NASH-related cirrhosis requiring liver transplantation (LT). ${ }^{14,15}$ The risk of developing progressive liver disease and associated extrahepatic diseases presents a challenge to the healthcare system to develop effective strategies in order to prevent an exponential increase in morbidity and mortality related to it. This review will focus on the growing burden of NAFLD, its outcomes and adverse associations with various extrahepatic diseases; of note, this review is not intended to discuss the therapeutic aspects of NAFLD and its complications.

\section{Global burden and rising prevalence}

According to current estimate, the global prevalence of NAFLD among the general population may be as high as one billion. ${ }^{2}$ In a recent meta-analysis of 86 studies, 
encompassing a sample size of 8,515,431 from 22 countries, the prevalence of NAFLD in the general population was $25.24 \%$, with the highest prevalence rates in the Middle East and South America. ${ }^{5}$ That meta-analysis also demonstrated an increased prevalence of NAFLD, from $15 \%$ in 2005 to $25 \%$ in 2010, and comparable prevalence rates between the West and the East.

The National Health and Nutrition Examination Surveys (NHANES) data collected from 1988 to 2008 show that the prevalence of NAFLD has doubled in the USA during that time period. From 1988 to 1994 , NAFLD accounted for $46.8 \%$ of chronic liver disease cases; from 1994 to 2004, its prevalence further increased to $62.84 \%$, and then to $75.1 \%$ from 2005 to $2008 .{ }^{16}$ NAFLD is no longer a disease confined to the Western world, as studies from China, Korea, Taiwan, Japan and India have also found a high community prevalence of NAFLD, ranging from $15-49.8 \%{ }^{5,17}$ (Table 1 ). Current USA projections using a Markov model indicate a $21 \%$ increase in NAFLD from 2015 to 2030 , leading to a $33.5 \%$ overall prevalence by 2030 . The projected increase in the prevalence of NASH is $63 \%$, which will cause a $168 \%$ increase in the number of patients with decompensated cirrhosis, and a $137 \%$ increase in the numbers of patients developing HCC by $2030 .{ }^{18}$ Thus, with growing prevalence rates of NAFLD affecting both adults and children, it is likely to emerge as the leading cause of end-stage liver disease in the years to come.

Obesity and T2DM are important risk factors for NAFLD. The prevalence of NAFLD is about $50-90 \%$ in obese subjects. ${ }^{19}$ The pooled prevalence of NAFLD in patients with T2DM is $59.67 \%$ ( $95 \%$ confidence interval (CI): $54.31-$ $64.92 \%$ ) according to a meta-analysis of 24 studies. ${ }^{20}$ The growing epidemic of obesity and T2DM have fueled an increasing prevalence of NAFLD worldwide. ${ }^{19-23}$ Moreover, obesity and T2DM also increase the risk of NAFLD progression to NASH, cirrhosis, and HCC. ${ }^{22,23}$ In Asia, NAFLD can occur in lean subjects with central obesity, which may be partly because of a higher metabolic activity of visceral fat and genetic predisposition, such as the patatin-like phospholipase domain-containing 3 (PNPLA3) polymorphism. ${ }^{24,25}$ It is worth noting that a wide variation in clinical presentation and sensitivity of diagnostic tools complicate diagnosis of NAFLD, often leading to an underestimate of the actual disease burden.

\section{Progression of NAFLD}

The natural course of liver disease progression in NAFLD is still incompletely defined. A subset of such patients develops progressive liver disease leading to NASH, cirrhosis, HCC, and liver failure (Fig. 1). Though early studies in 1990's suggested that SS does not progress to NASH or cirrhosis, subsequent studies with paired liver biopsies have shown that SS is more progressive than originally believed. ${ }^{26-28}$ Apart from components of MetS, genetic polymorphisms, such as PNPLA3 I148M gene and transmembrane 6 superfamily member 2 E167K gene variants, have a significant impact on NAFLD susceptibility and progression. ${ }^{25}$ Identification of such variants may help to identify NAFLD patients at higher risk for liver disease progression and HCC.

\section{Progression from SS and NASH}

Prospective studies have revealed progression from SS to $\mathrm{NASH}$ in $23-44 \%$ of patients over a period of 26 months to 6.6 years. ${ }^{7,28}$ In a meta-analysis of 11 studies including 411 patients with paired liver biopsy performed at least 1 year apart, liver fibrosis progression occurred not only in patients with NASH but also in patients with nonalcoholic fatty liver (NAFL), defined as SS alone or associated with mild inflammation. One stage of fibrosis progression occurred over 14.3 years in patients with NAFL (95\% CI: $9.1-50.0$ years) and 7.1 years among patients with NASH (95\% CI: 4.8-14.3 years). ${ }^{29}$ A very slow rate of progression of SS may partly account for the discrepancy between clinical and histological studies, as such patients may die from other causes before developing advanced liver disease. In a systematic review of 10 studies, Argo et al. have found that $37.6 \%$ of 221 patients with NASH had progressive fibrosis over a mean follow-up interval of 5.3 years. ${ }^{30} \mathrm{~A}$ recent meta-analysis also revealed occurrence of fibrosis progression in $41 \%$ of NASH patients, with $20 \%$ of them identified as being rapid progressors. ${ }^{5}$ Yet

Table 1. Recent Population-based prevalence studies on NAFLD based on ultrasonography

\begin{tabular}{|c|c|c|c|c|}
\hline Study & Country/region & Year published & Screened population, $n$ & NAFLD detected, $n(\%)$ \\
\hline Kim et al. ${ }^{56}$ & USA & 2013 & 12317 & $4188(34.00 \%)$ \\
\hline Caballería et al. ${ }^{111}$ & Spain & 2010 & 766 & $198(25.80 \%)$ \\
\hline Suomela et al. ${ }^{112}$ & Finland & 2015 & 1621 & $246(15.20 \%)$ \\
\hline van der Voort et al. ${ }^{95}$ & Netherlands & 2014 & 2292 & $779(34.00 \%)$ \\
\hline Ruhl et al. ${ }^{113}$ & USA & 2013 & 12232 & $2446(20.00 \%)$ \\
\hline Shen et al. ${ }^{114}$ & Taiwan & 2014 & 6511 & $1769(27.17 \%)$ \\
\hline Younossi et al. ${ }^{115}$ & USA & 2013 & 6709 & $1448(22.00 \%)$ \\
\hline Chang et al. ${ }^{116}$ & South Korea & 2013 & 43166 & $11652(26.99 \%)$ \\
\hline Cai et al. ${ }^{117}$ & China & 2013 & 10605 & $3906(36.83 \%)$ \\
\hline Dassanayake et al. ${ }^{118}$ & Sri Lanka & 2009 & 2985 & $974(32.63 \%)$ \\
\hline Kim et al. ${ }^{65}$ & South Korea & 2012 & 4023 & $1617(40.20 \%)$ \\
\hline Chalmers et al. ${ }^{17}$ & India & 2019 & 2158 & $1075(49.8 \%)$ \\
\hline
\end{tabular}

Abbreviation: NAFLD, nonalcoholic fatty liver disease. 


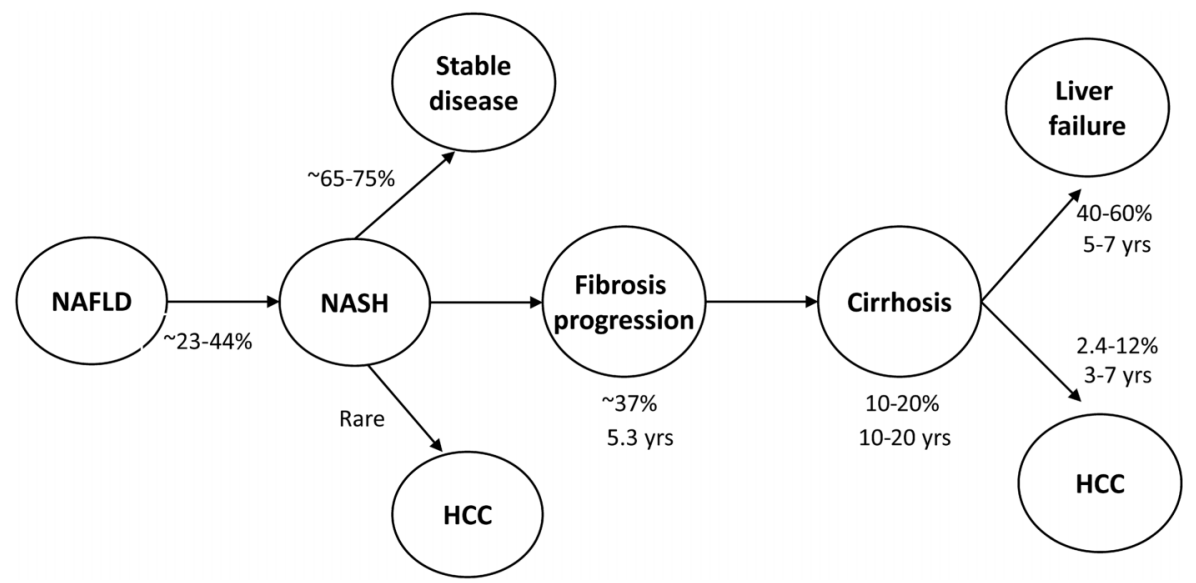

Fig. 1. Progression of liver disease in patients with NAFLD. Data adapted from references: 9, 27, 28, 30 and 40.

Abbreviations: HCC, hepatocellular carcinoma; NAFL, nonalcoholic fatty liver; NASH, nonalcoholic steatohepatitis.

another study has revealed a rapid fibrosis progression in one-third of NASH patients who had any-stage of fibrosis progression. ${ }^{31}$ To summarize, studies utilizing paired liver biopsies suggest that approximately $23-44 \%$ of patients with SS progress to NASH and $37-41 \%$ of patients with NASH develop progressive fibrosis.

\section{NASH-cryptogenic cirrhosis}

Clinical-histological study has revealed silent cirrhosis in $10 \%$ $(8 / 80)$ of NAFLD patients with normal liver enzymes. ${ }^{32}$ Around $9-25 \%$ of patients with NASH progress to cirrhosis over a period of 10-20 years. In a recent study, French investigators identified 125,052 NAFLD/NASH patients from the French National Database on Hospital Care, of whom 1.2\%, $6.3 \%$, and $0.9 \%$ were diagnosed with compensated cirrhosis, decompensated cirrhosis, and HCC respectively. During 7 years of follow-up, $5.6 \%$ of the NAFLD/NASH patients progressed to cirrhosis and $27.5 \%$ of the compensated cirrhosis patients developed decompensation. ${ }^{33}$ Powell et al. ${ }^{34}$ have suggested that NASH should be recognized as a potential cause of cryptogenic cirrhosis (CC).

Many of the patients with CC have features of MetS in varying proportions. ${ }^{35,36}$ However, needle biopsy studies have failed to demonstrate histological features of NASH in patients with CC. It seems that the features of NASH usually regress concurrently with fibrosis progression. ${ }^{34,35}$ In contrast to studies based on needle biopsy samples, explants from CC patients undergoing LT have revealed steatosis $(80 \%)$ and ballooning $(70 \%)$ in a significant proportion. ${ }^{37} \mathrm{~A}$ study from India that assessed explants from patients with CC revealed NASH to be the etiology in $63 \%$ patients. ${ }^{38}$ Another study of explants from CC revealed NASH to be the most common etiology (33\%). ${ }^{34}$ Moreover, the recurrence of steatosis in the allograft of CC patients is remarkably high (100\% in 5 years). ${ }^{39}$ Therefore, NASH-cirrhosis cases appear to constitute a significant proportion of patients previously labelled as CC.

\section{NAFLD and HCC}

$\mathrm{HCC}$ is the second leading cause of cancer - related death worldwide. NAFLD has emerged as one of the leading causes of HCC in recent years. Multiple risk factors, such as components of MetS, ethnicity and hepatic siderosis, appear to have an incremental effect on the risk of developing HCC among NAFLD patients. The cumulative incidence of HCC in patients with NASH-related cirrhosis is quite high, ranging from $2.4 \%$ over 7 years to $12.8 \%$ over 3 years. ${ }^{40}$ However, alarmingly, HCC can develop de novo in patients with NASH in the absence of cirrhosis. ${ }^{41,42}$ Kawada et al., ${ }^{43}$ in a study of $1,168 \mathrm{HCC}$ patients who underwent hepatic resection, found NASH as an etiology of HCC in 8 patients, 6 of who (75\%) had noncirrhotic NASH. Similarly, Takuma et al. ${ }^{44}$ reported 7 out of their studied $11(65 \%)$ patients with NASH-related HCC had noncirrhotic liver. In a review of 94 published cases of $\mathrm{NASH}$-related HCC, the patients were found to be predominantly elderly males, with $26 \%$ having noncirrhotic liver and the majority $(69 \%)$ having large (mean size $3.5 \mathrm{~cm}$ ) and multifocal HCC. ${ }^{44}$

Several reports have confirmed the increasing burden of NAFLD - related HCC worldwide. A recent large population based Surveillance, Epidemiology and End Results (known as the SEER) study has demonstrated a $9 \%$ annual increase in NAFLD-related HCC between 2004 and 2009. ${ }^{45}$ Dyson et al. ${ }^{46}$ noted a nearly 10 - fold increase in NAFLD - related HCC cases in the UK from 2000 to 2010 . Another study from a hepatitis B - endemic area in Korea has also demonstrated an increasing proportion of NAFLD - related HCC cases over time. ${ }^{47}$ Moreover, patients with NAFLD-related HCC had a shorter survival time, more cardiovascular events, and more cancer-related mortality than patients without NAFLD. ${ }^{48}$ In a study from Germany, where 1119 patients with HCC treated in an 11 year period were retrospectively analyzed, the overall survival among the patients with $\mathrm{NASH}$-related HCC $(n=45)$ was lower compared to those with HCC of other etiologies. ${ }^{49}$ However, it appears that the worse natural history in such patients is not related to a more aggressive behavior of NAFLD - HCC, but mainly to detection at a later stage.

\section{Long-term outcomes}

Multiple studies have found that the overall mortality in NAFLD patients is higher than that in matched individuals from a healthy population. ${ }^{50-55} \mathrm{~A}$ community-based cohort 
study with mean follow-up duration of 7.6 years found that mortality in NAFLD patients was significantly higher than in the general population (standardized mortality ratio of 1.34; 95\% CI: 1.003-1.76). Death was most commonly due to malignancy and CVD. ${ }^{50}$ Using the third set of NHANES data, Ong et al. ${ }^{51}$ found NAFLD to be associated with higher overall (hazard ratio (HR): $1.038 ; 95 \%$ CI 1.036-1.041) and liverrelated (HR: 9.32; 95\% CI 9.21-9.43) mortality compared with the reference population. In both studies, liver disease was the third leading cause of death among NAFLD subjects.

Two recent longitudinal studies have uniformly found that stage of liver fibrosis irrespective of severity of hepatic necroinflammation is independently associated with overall and disease-specific mortality in patients with NAFLD. ${ }^{50,53}$ In one study involving 619 NAFLD patients with median follow-up period of 12.6 years, the risk of death or LT $(n=193)$ increased progressively with increasing stages of fibrosis (HR for stage 1: 1.88 , stage 2: 2.89 , stage $3: 3.76$, and stage 4: 10.9). Patients with fibrosis, regardless of NASH, had shorter survival times than patients without fibrosis. ${ }^{50}$ Another longitudinal study with mean follow-up of 26.4 years found that NAFLD patients $(n=229)$ had an increased mortality compared with the reference population (HR: 1.29; 95\% CI 1.04-1.59) and CVD constituted the most common cause of death. Overall mortality was not increased in patients with NASH and mild fibrosis, whereas patients with fibrosis stage $>2$, irrespective of $\mathrm{NASH}$, had increased mortality (HR: $3.3 ; 95 \%$ CI 2.27-4.76, $p<0.001$ )..$^{53}$

In a meta-analysis of seven studies with follow-up ranging from 7.3-24 years, liver -elated mortality was higher in patients with NASH compared to those with SS (OR: 5.71; $95 \%$ CI: $2.31-14.13) .{ }^{54} \mathrm{Kim}$ et al., ${ }^{56}$ in a large prospective cohort study of 11,154 USA adult participants from the NHANES population found that NAFLD itself did not increase the risk of mortality. However, advanced fibrosis, as determined by noninvasive fibrosis markers, significantly predicted the mortality, mainly from CVD causes, independent of other known factors. In a systematic review and meta-analysis of five studies including 1,495 NAFLD patients with 17,452 patient years of follow-up, Dulai et al. ${ }^{57}$ found an increased risk for all-cause mortality with increase in the stage of fibrosis, and such risk was more pronounced with regard to liverrelated mortality.

It appears that higher stages of liver fibrosis are a strong determinant of all-cause mortality in NAFLD, most likely because of the pronounced effect on liver-related mortality, whereas CVD accounts for an increased proportion of mortality at lower stages of fibrosis. Thus, compared with the general population, NAFLD increases the risk of liverrelated, cardiovascular and all-cause mortality, and the impact of NAFLD on mortality appears to differ according to its severity (Table 2 ). The disparity in estimates of risk across studies might be attributed to variations in characteristics of study populations or follow-up.

\section{Extrahepatic association of NAFLD}

NAFLD is closely associated with several extrahepatic diseases, such as T2DM, CVD, malignancy, CKD, OSA, and PCOS (Fig. 2). These associations do not truly represent extrahepatic manifestations of NAFLD. However, the implications of such association may influence clinical evaluation and treatment decisions in NAFLD patients. Although these associations may result from common risk factors, there are lines of evidence to suggest that NAFLD is associated with many of these diagnoses, independent of traditional risk factors, such as components of MetS. Also, for some of the diseases, the association appears to be bidirectional. Therefore, severity of NAFLD may influence the severity of associated disease and vice versa. Similarly, management of one condition may influence management of the associated one.

\section{T2DM}

The association between NAFLD and T2DM is complex and bidirectional. NAFLD is not only a consequence but also a cause of T2DM. NAFLD is associated with increased risk of developing DM after adjustment for several metabolic confounders. ${ }^{54,58,59}$ Two large meta-analyses have confirmed the association between NAFLD and incident T2DM. ${ }^{54}$ In a prospective study of 129 biopsy-proven NAFLD patients, $78 \%$ developed either T2DM (58\%) or impaired glucose tolerance $(20 \%)$ during the 13.7 years follow-up. ${ }^{58}$ Moreover, the risk of incident T2DM was threefold higher among patients with NASH compared to those with SS. Moreover, T2DM increases the risk of NAFLD progression to NASH, cirrhosis, and $\mathrm{HCC}^{23}$

Because of systemic insulin resistance (IR), NAFLD worsens the glycemic control in patients with T2DM. In diabetic subjects, NAFLD increases risk of all-cause mortality by 2.2 -fold compared with those without NAFLD. ${ }^{60}$ NAFLD and T2DM interact adversely to enhance the risk of atherosclerosis, CKD, and retinopathy. ${ }^{23}$ Substantial evidence links NAFLD with an increased risk of developing CVD and arrhythmic complications in patients with DM. ${ }^{61}$ Thus, the coexistence of NAFLD and DM increases the risk of developing not only the more severe forms of NAFLD but also the vascular complications of DM and all-cause mortality.

\section{CVD}

Several studies have unequivocally demonstrated a strong association between NAFLD and increased risk of CVD. NAFLD has been linked with increased biomarkers of endothelial dysfunction, ${ }^{62}$ increased carotid artery intima-media thickness, ${ }^{63}$ increased arterial stiffness, ${ }^{64}$ coronary artery calcification, ${ }^{65}$ and impaired flow-mediated vasodilatation. ${ }^{66} \mathrm{~A}$ recent meta-analysis of 27 studies supported the association of NAFLD with markers of subclinical atherosclerosis independent of traditional CVD risk factors and MetS. ${ }^{67}$ Moreover, persistent and progression of NAFLD is associated with increased risk and progression of subclinical carotid atherosclerosis, in a study comparing to subjects without NAFLD and those with regression of NAFLD. ${ }^{68}$

The widely prevalent dyslipidemia in NAFLD patients is highly atherogenic, being characterized by hypertriglyceridemia, high levels of low-density lipoprotein cholesterol, and low levels of high-density lipoprotein cholesterol-all of which are key risk factors for CVD. ${ }^{69}$ Studies in patients with NAFLD have shown abnormal left ventricular morphology and diastolic dysfunction when compared with controls. ${ }^{70,71}$ Various factors have been implicated in the causation of left ventricular dysfunction in NAFLD, including hyperinsulinemiainduced myocyte growth and interstitial fibrosis, alteration in myocardial metabolism of fatty acids, upregulation of angiotensin II (a neurohormone), decrease in myocardial perfusion reserve, and increase in aortic stiffness. 
Kumar R. et al: NAFLD: a growing threat

Table 2. Community-based longitudinal studies determining all-cause and cause-specific mortality in patients with NAFLD

\begin{tabular}{|c|c|c|c|c|}
\hline Study, year & Population & Follow-up & $\begin{array}{l}\text { Diagnostic } \\
\text { method }\end{array}$ & Results \\
\hline $\begin{array}{l}\text { Adams et al. }{ }^{119}, \\
2005\end{array}$ & $\begin{array}{l}420 \text { community-based USA } \\
\text { NAFLD patients }\end{array}$ & 7.6 years & $\begin{array}{l}\text { Histology and } \\
\text { ultrasonography }\end{array}$ & $\begin{array}{l}\text { Patients with NAFLD had higher rates of } \\
\text { all-cause, CVD and liver-related } \\
\text { mortality than the matched general } \\
\text { population (standardized mortality } \\
\text { ratio:B } 1.34 ; 95 \% \mathrm{CI}: 1.003-1.76 \text { ) }\end{array}$ \\
\hline $\begin{array}{l}\text { Ekstedt et al. }{ }^{58}, \\
2006\end{array}$ & $\begin{array}{l}129 \text { Swedish biopsy-proven } \\
\text { NAFLD patients }\end{array}$ & 13.7 years & Histology & $\begin{array}{l}\text { Mortality was not increased in patients } \\
\text { with simple steatosis but patients with } \\
\text { NASH had higher rates of all-cause } \\
\text { ( } \sim 2 \text {-fold }) \text {, cardiovascular }(\sim 2 \text {-fold }) \text { and } \\
\text { liver-related }(\sim 10 \text {-fold }) \text { mortality than } \\
\text { the matched reference population }\end{array}$ \\
\hline $\begin{array}{l}\text { Rafiq et al. }{ }^{121}, \\
2009\end{array}$ & $\begin{array}{l}173 \text { USA patients with } \\
\text { biopsy-proven NAFLD }\end{array}$ & 13 years & Histology & $\begin{array}{l}\text { All-cause mortality did not differ } \\
\text { between the NAFLD subtypes, but liver- } \\
\text { related mortality was higher in patients } \\
\text { with NASH } \\
\text { The most common causes of mortality } \\
\text { were CVD, malignancy and liver-related } \\
\text { complications }\end{array}$ \\
\hline $\begin{array}{l}\text { Söderberg } \\
\text { et al. }{ }^{52}, 2010\end{array}$ & $\begin{array}{l}256 \text { Swedish subjects with } \\
\text { raised liver enzymes, } \\
\text { including } 118 \text { biopsy-proven } \\
\text { NAFLD }\end{array}$ & 28 years & Histology & $\begin{array}{l}40 \% \text { of the } 118 \text { NAFLD subjects died } \\
\text { during follow-up. Compared with the } \\
\text { matched Swedish population, subjects } \\
\text { with NAFLD exhibited } 69 \% \text { increased } \\
\text { mortality, more so with NASH }(86 \%)\end{array}$ \\
\hline $\begin{array}{l}\text { Ekstedt et al. }{ }^{53}, \\
2015\end{array}$ & $\begin{array}{l}229 \text { Swedish patients with } \\
\text { biopsy-proven NAFLD }\end{array}$ & $\begin{array}{l}26.4 \pm 5.6 \\
\text { years }\end{array}$ & Histology & $\begin{array}{l}\text { Patients with NAFLD have increased } \\
\text { all-cause mortality (HR: } 1.29,95 \% \mathrm{CI} \text { : } \\
1.04-1.59 \text { ), with a high risk of death } \\
\text { from CVD and liver-related disease. The } \\
\text { fibrosis stage rather than presence of } \\
\text { NASH predicts the mortality }\end{array}$ \\
\hline $\begin{array}{l}\text { Jepsen et al. }{ }^{38} \\
2003\end{array}$ & $\begin{array}{l}\text { 7,372 Danish patients with } \\
\text { fatty liver, including } 1,800 \\
\text { patients with NAFLD }\end{array}$ & 6.2 years & $\begin{array}{l}\text { Ultrasound and } \\
\text { liver enzymes }\end{array}$ & $\begin{array}{l}\text { Patients with NAFLD had higher rates of } \\
\text { all-cause ( } 2.6 \text {-fold), cardiovascular } \\
\text { ( } 2.1 \text {-fold) and liver-related ( } 19.7 \text {-fold) } \\
\text { mortality than the general population }\end{array}$ \\
\hline $\begin{array}{l}\text { Haring et al. }{ }^{120}, \\
2009\end{array}$ & $\begin{array}{l}4,160 \text { community-based } \\
\text { cohort of German adult } \\
\text { subjects }\end{array}$ & 7.3 years & Ultrasound & $\begin{array}{l}\text { NAFLD was independently associated } \\
\text { with increased risk of all-cause and CVD } \\
\text { mortality in men (HR: } 6.2,95 \% \text { CI: } \\
1.2-31.6 \text { ) }\end{array}$ \\
\hline $\begin{array}{l}\text { Zhou et al. }{ }^{55}, \\
2012\end{array}$ & $\begin{array}{l}3,543 \text { community-based } \\
\text { cohort study of Chinese } \\
\text { adult subjects }\end{array}$ & 4 years & Ultrasound & $\begin{array}{l}\text { Patients with NAFLD had } \sim 3 \text {-fold higher } \\
\text { rates of all-cause and CVD mortality } \\
\text { than those without NAFLD }\end{array}$ \\
\hline $\begin{array}{l}\text { Kim et al. }{ }^{56}, \\
2013\end{array}$ & $\begin{array}{l}11,154 \text { USA adult } \\
\text { participants, including } \\
34.0 \% \text { NAFLD, from the } \\
\text { Third NHANES-1988-94. }\end{array}$ & 14.5 years & $\begin{array}{l}\text { Ultrasound and } \\
\text { noninvasive } \\
\text { markers of liver } \\
\text { fibrosis }\end{array}$ & $\begin{array}{l}\text { NAFLD with advanced fibrosis, not } \\
\text { NAFLD in general, is associated with } \\
\text { increased mortality independent of } \\
\text { other known factors }\end{array}$ \\
\hline $\begin{array}{l}\text { Zeb et al. }{ }^{122}, \\
2016\end{array}$ & $\begin{array}{l}4,119 \text { USA adult subjects, } \\
\text { including } 728 \text { NAFLD, } \\
\text { without CVD at baseline }\end{array}$ & $\begin{array}{l}\text { Median } 7.6 \\
\text { years }\end{array}$ & $\begin{array}{l}\text { Computed } \\
\text { tomography }\end{array}$ & $\begin{array}{l}\text { Overall } 253 \text { deaths reported, including } \\
40 \text { NAFLD subjects. NAFLD was } \\
\text { independently associated with incident } \\
\text { CVD and all-cause event (HR: } 1.42 \text {, } \\
95 \% \text { CI: } 1.00-2.03 \text { ) }\end{array}$ \\
\hline
\end{tabular}

Abbreviations: CVD, cardiovascular disease; NAFLD, nonalcoholic fatty liver disease; NASH, nonalcoholic steatohepatitis.

NAFLD is also associated with an increased risk of atrial fibrillation. ${ }^{72}$ NAFLD has also been reported as independently associated with QT prolongation. ${ }^{73}$ Notably, the duration of the QT interval is a predictor for CVD death in the general population, and a prolonged QT interval increases the risk of cardiac arrhythmias and sudden cardiac death. ${ }^{74}$

NAFLD contributes to the prothrombotic state by increasing plasma levels of plasminogen activator inhibitor 1 , the 


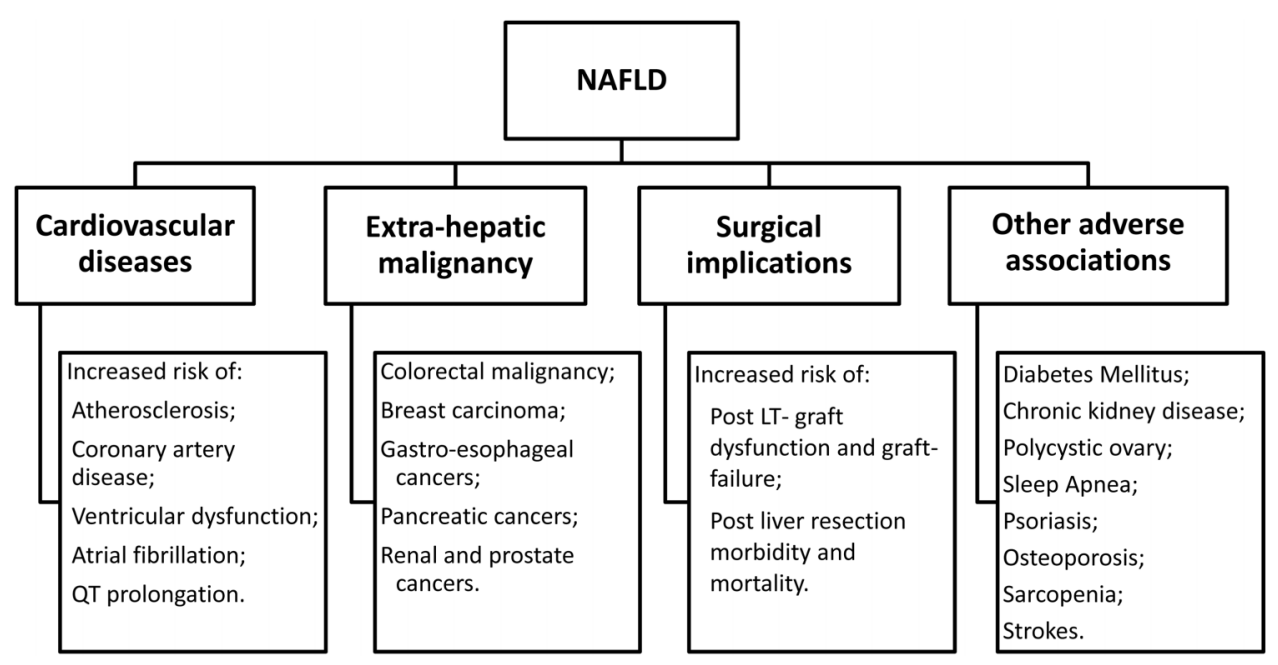

Fig. 2. Association of NAFLD with cardiovascular diseases, extrahepatic malignancy, surgical complications, and various other diseases.

Abbreviations: LT, liver transplantation; NAFLD, nonalcoholic fatty liver disease.

elevated levels of which are related to increased risk of myocardial infarction. ${ }^{75}$ In a recent prospective study among patients with clinical indication of coronary angiogram ( $n=612$ ), the presence of NAFLD was associated with severity of coronary artery stenosis and need for coronary intervention. ${ }^{76}$ In a large meta-analysis of 164,494 participants from 21 cross-sectional and 13 cohort studies, NAFLD was associated with an increased risk of incident (HR: 1.37; 95\% CI: $1.10-1.72$ ) and prevalent (OR: $1.81 ; 95 \%$ CI: $1.23-$ 2.66) CVD but not with CVD mortality. ${ }^{77}$ However, there was marked heterogeneity among studies and nonuniform definition of important variables, including DM, which could have affected the results of mortality. Moreover, another metaanalysis of 40 studies assessing the natural history of NAFLD revealed that patients with NAFLD, irrespective of SS or $\mathrm{NASH}$, had a considerably greater risk of CVD mortality than the matched control population. ${ }^{54}$

Many prospective studies have demonstrated that CVDrelated death occurs in higher proportion than liver-related death among patients with NAFLD. ${ }^{50,51} \mathrm{~A}$ meta-analysis of a total 16 observational studies with 34,043 adult individuals, including $36.3 \%$ NAFLD and approximately 2,600 CVD outcomes over a median period of 6.9 years, revealed that NAFLD is significantly associated with an increased risk of fatal and nonfatal cardiovascular events (OR: 1.64). However, the observational design of the studies included does not prove that NAFLD causes CVD. ${ }^{78}$ Thus, there seems to be little doubt that NAFLD is associated with increased incidence and prevalence of CVD, some controversies surround as to whether NAFLD by itself is associated with increased CVD mortality. Also, whether the association between NAFLD and CVD is because of the shared risk factors or NAFLD itself confers an additional risk is the subject of further extensive scrutiny.

\section{Extrahepatic malignancy}

NAFLD has been associated with several extrahepatic malignancies. Malignancy is among the leading cause of death in NAFLD patients. ${ }^{50,51,54}$ In meta-analyses of seven longitudinal studies with follow-up ranging from 7.3 to 24 years, malignancy was the most common ( $28 \%$ ) cause of death in NAFLD. ${ }^{54}$ In a recent longitudinal study comprising a community cohort of 4,722 NAFLD and 14,441 age- and sexmatched control subjects, 2,224 incident cancers occurred during a median follow-up of 8 years and NAFLD was associated with $90 \%$ higher risk of developing cancers. ${ }^{79}$ The highest increase in the risk was noted for HCC, followed by uterine, gastric, pancreatic and colonic cancer. Moreover, the association between obesity and cancer risk was small in the absence of NAFLD, suggesting that NAFLD may potentiate obesity-cancer relationship. ${ }^{79}$

In a cohort study of 129 biopsy-proven NAFLD patients, $5.6 \%$ of the patients with NASH died because of extrahepatic malignancy during a mean follow-up of 13.7 years. ${ }^{58}$ Several studies have found a higher prevalence of colorectal neoplasm in patients with NAFLD compared to patients without NAFLD. ${ }^{80-82}$ A large cohort study $(n=5517)$ from Korea has found a two-fold increase in the occurrence of colorectal adenoma and a three-fold increase in the risk of colorectal cancer in patients with NAFLD compared to controls. ${ }^{80}$ Another study revealed that among NAFLD, patients with $\mathrm{NASH}$ have a higher prevalence of adenomas ( $51.0 \%$ vs. $25.6 \%$ ) and advanced neoplasms (34.7\% vs. $14.0 \%$ ) than those with SS. Moreover, NASH remained significantly associated with a risk of adenomas and advanced neoplasms after adjusting for demographic and metabolic factors. ${ }^{81}$

In a retrospective cohort study on 1,522 subjects who underwent two consecutive colonoscopies between 2003 and 2010, NAFLD was an independent risk factor (OR: $1.45 ; 95 \%$ CI: 1.07-1.98) for adenoma formation after a negative baseline colonoscopy. ${ }^{82}$ The adenoma group had a higher prevalence of NAFLD than the non-adenoma group $(55.6 \%$ vs. $38.8 \% ; p<0.05)$. NAFLD patients are more likely to have multiple polyps localized more often in the right hemicolon. In a case-control study, NAFLD was found to have a significant association with breast cancer. ${ }^{83}$ NAFLD has also been found to be associated with malignancy of the esophagus, stomach, pancreas, kidney, and prostate.9,54,79 However, concurrent presence of features of MetS and too little available data limit drawing definite conclusions about a causal role of NAFLD in such association. 


\section{CKD}

The link between NAFLD and CKD has drawn considerable attention during recent times. Various studies have suggested that NAFLD can accelerate the development and progression of CKD independent of traditional risk factors. ${ }^{10,84,85}$ A recent meta-analysis, that included near 64,000 subjects, found that NAFLD was associated with an approximately 2 -fold increase in risk of both prevalent (OR: 2.12; 95\% CI: $1.69-2.66$ ) and incident CKD (HR: $1.79 ; 95 \%$ CI: $1.65-1.95) .{ }^{84}$ Furthermore, histologically severe NAFLD is more positively correlated with CKD. Both NASH and NAFLD with advanced fibrosis are associated with a higher prevalence (OR: 2.53 for NASH, OR: 5.20 for advanced fibrosis) and incidence of CKD (HR: 2.12 for NASH, HR: 3.29 for advanced fibrosis), as compared to those with SS. ${ }^{84}$

In a large longitudinal study, NAFLD was found to be associated with declining renal function in CKD patients independent of traditional risk factors, and the association was stronger in patients with advanced NAFLD. ${ }^{85}$ The pathophysiologic basis of the linkage between the two appear to be multifactorial. The pro-inflammatory milieu in NAFLD along with IR, dyslipidemia, oxidative stress, hypertension, and the activated renin-angiotensin system may hasten the development and progression of CKD. Compared to other etiologies of cirrhosis, the risk of CKD and requirement of simultaneous liver-kidney transplantation are greater in patients with NASH-related cirrhosis. ${ }^{86}$ Furthermore, CKD may aggravate NAFLD through uremic toxins, intestinal dysbiosis, altered gut-barrier function, and alterations in glucocorticoid metabolism. ${ }^{87}$ Interestingly, there is evidence to suggest that in patients with $\mathrm{NASH}$, improvement in liver histology by lifestyle modification leads to improved kidney function. ${ }^{85}$

\section{PCOS}

PCOS is one of the most common endocrine disorders in women during reproductive ages. It is associated with a plethora of metabolic consequences, including glucose intolerance, dyslipidemia, and NAFLD. Several studies have consistently found that the prevalence and severity of NAFLD is markedly increased in women with PCOS, independent of coexisting features of MetS. ${ }^{88}$ A recent systematic review and meta-analysis of 17 studies has revealed that PCOS patients ( $n=2,734$ ) have increased prevalence of NAFLD (OR: 2.54, 95\% CI 2.19-2.95) and the presence of NAFLD among them is associated with hyperandrogenism, in addition to IR and adiposity. ${ }^{89}$ The prevalence of NAFLD among women with PCOS is estimated to vary from $15 \%$ to $55 \%$, whereas amongst the reproductive-aged women with NAFLD, the prevalence of PCOS is as high as $71 \% .{ }^{90}$

\section{OSA}

OSA is strongly associated with NAFLD independent of traditional risk factors. In a meta-analysis of over 2,000 subjects from 18 studies, OSA was associated with an increased risk of NAFLD (OR: 2.99), NASH (OR: 2.37), and advanced fibrosis (OR: 2.30). ${ }^{91}$ This association is related to the degree of nocturnal hypoxemia caused by repetitive upper airway obstruction during sleep. Intermittent hypoxia can result in oxidative stress, IR, abnormal lipid metabolism, overactivation of the sympathetic nervous system, inflammation, and mitochondrial dysfunction, each of which plays important roles in development and progression of NAFLD. ${ }^{92}$ Intermittent hypoxia activates hypoxia-inducible factors, which leads to increased synthesis of hepatic fat, upregulated hepatic inflammation, and fibrosis. The chronic intermittent hypoxia in morbidly obese subjects contributes to the severity of hepatic necroinflammation and fibrosis independent of adiposity. ${ }^{93}$ Furthermore, NAFLD in patients with OSA is associated with higher CVD risks. Minville et al. ${ }^{94}$ have recently demonstrated that in patients with OSA, hepatic steatosis was independently associated with endothelial dysfunction after adjustment for confounders. Therefore, among obese patients with OSA, screening for the presence of underlying NAFLD and subsequent monitoring for NAFLD progression should be considered. In patients with NAFLD, treatment of OSA with continuous positive airway pressure may impact outcomes of future CVD.

\section{Psoriasis}

NAFLD is highly prevalent in patients with psoriasis. In a large prospective population-based cohort study of 2,292 subjects with $118(5.1 \%)$ patients with psoriasis, NAFLD prevalence was higher among those with psoriasis (46.2\% vs. $33.3 \%$ ) even after adjustment for important risk factors. ${ }^{95}$ The prevalence of $\mathrm{NASH}$ in patients with psoriasis is much higher $(22 \%)$ than that in the general population (2-6\%). Moreover, data also suggest that the presence of NAFLD may increase severity of psoriasis. ${ }^{96,97}$ Future studies are needed to assess whether there is a causal relationship between NAFLD and psoriasis.

\section{Osteoporosis}

Several studies have demonstrated that NAFLD patients have lower bone mineral density compared to non-NAFLD subjects. ${ }^{98}$ In a study from China, NAFLD was independently associated with a $\sim 2.5$-fold increased odds of osteoporotic fractures among men. ${ }^{99} \mathrm{~A}$ recent meta-analysis of six studies has revealed that obese children with NAFLD are more susceptible to osteoporosis than children with only obesity. ${ }^{13}$ The potential contribution of NAFLD to development of osteoporosis warrants further study. Chronic inflammatory processes, vitamin D deficiency, disturbances of growth hormone/insulin-like growth factor 1 axis are the proposed pathophysiological factors linking NAFLD with decreased bone mass.

\section{Sarcopenia}

NAFLD has been recently associated with sarcopenia which is defined as a generalized, and progressive and loss of skeletal muscle mass, quality, and strength. 100,101 Sarcopenia is associated with increased risks and histological severity of NAFLD, independent of obesity and metabolic risk factors. ${ }^{100}$ In a longitudinal study, Kim et al. ${ }^{101}$ has demonstrated that increases in relative skeletal muscle mass over time had significant beneficial association with incident NAFLD (adjusted HR: $0.69 ; 95 \% \mathrm{CI}: 0.59-0.82$ ) and resolution of baseline NAFLD (adjusted HR: 4.17 ; $95 \%$ CI: $1.90-$ 6.17). The pathophysiological mechanisms linking sarcopenia and NAFLD may include IR and chronic inflammation. IR promotes accumulation of triglycerides in muscles and exacerbates protein catabolism in association with the chronic inflammatory milieu, leading to muscle depletion. 


\section{CVA}

NAFLD appears to be associated with an increased risk and severity of stroke as well as with a worse functional outcome in stroke patients. In a prospective study including a total of 25,800 subjects, Hadda et al. ${ }^{102}$ found an increased frequency of CVA in NAFLD compared to the controls. A metaanalysis of seven studies with a total of 6,183 subjects revealed a significant association of NAFLD with elevated risk of CVA. ${ }^{12}$ Also, there are data to suggest a role of NAFLD in subclinical ischemic stroke and cognitive impairments. ${ }^{102}$ These observations are clinically relevant because strategies to prevent the progression of asymptomatic brain lesions to overt CVA can be explored in patients with NAFLD. Further studies are warranted to throw more light on these aspects.

\section{$\boldsymbol{A P}$}

NAFLD increases the severity of AP. A recent study demonstrated that the presence of NAFLD at admission portends a higher risk of severe and moderately severe AP, as well as a higher risk of organ failure. ${ }^{11}$ The mechanism by which NAFLD exacerbates pancreatitis remains unclear. The potential reasons could be imbalance of adipocytokines, increased activity of hepatic Kupffer cells, and reduction of alpha-1-antitrypsin levels. Pancreatic steatosis, which is frequently associated with NAFLD, may lead to a higher incidence of AP and may be an etiological factor in pancreatic cancer.

\section{Surgical implications of NAFLD}

\section{Post-liver resection liver failure}

A normal liver has remarkable capacity to regenerate, which makes it possible for surgeons to do a large liver resection without causing significant hepatic impairment. However, extended liver resection may lead to the development of progressive liver failure in the postoperative period which is associated with very high mortality rate. ${ }^{103}$ Steatotic liver have poor ability to regenerate and reduced tolerance against ischemic injury. Therefore, patients with NAFLD are at higher risk of post-liver resection liver failure. In a series of 135 patients who had undergone major hepatic resection at the Mayo Clinic, acute liver failure occurred in $14 \%$ of patients with fatty liver versus $4 \%$ in those with normal liver. ${ }^{104}$ In a cohort of 478 liver resection patients, Belghiti et al. ${ }^{105} \mathrm{dem}-$ onstrated that steatosis was an independent risk factor for postoperative complications. Another study on outcome after liver-resection for colorectal liver metastases in 406 patients has found that patients with steatohepatitis have a significantly higher 90-day mortality than those without it (14.7 vs. $1.6 \%$; OR: 10.5). ${ }^{106}$ In conclusion, major hepatic resection of steatotic liver, particularly in patients with NASH, is associated with increased risk of liver failure and death.

\section{Influence on $L T$}

Transplantation of steatotic grafts is associated with an increased risk of primary nonfunction, early allograft dysfunction, and posttransplant vascular and biliary complications in cadaveric as well as living-donor LT. ${ }^{107}$ A study involving large series of LT patients has demonstrated that patients receiving up to $30 \%$ of fatty liver had a higher rate of primary nonfunction
( $5.1 \%$ vs. $1.8 \%)$ and worse patient ( $77 \%$ vs. $91 \%$ ) and graft ( $70 \%$ vs. $82 \%$ ) survival at 2 years compared to patients receiving a nonsteatotic graft. ${ }^{108}$ NAFLD is an independent predictor of occurrence of post-LT MetS that increases the risk of steatosis in the graft liver. ${ }^{109,110}$ Within a few months of LT, steatosis developed in $60-100 \%$ of the patients and $\mathrm{NASH}$ in $10-40 \%$ of the patients. Approximately $10 \%$ of the patients progressed to advanced fibrosis or cirrhosis in a decade. ${ }^{110}$

In conclusion, NAFLD is highly prevalent in the general population, and its prevalence is expected to increase in the coming years. It has emerged as one of the leading causes of cirrhosis and $\mathrm{HCC}$ in recent years and is a growing indication for LT. NAFLD is associated with various extrahepatic diseases and increased risk of all-cause mortality. Increased awareness about consequences of NAFLD and development of strategies to change the course of this disease are needed to control its emerging global threat. The optimal treatment of NAFLD remains a clinical challenge, as there is no approved pharmacotherapies. While traditional pharmacological therapies, such as insulin sensitizer (pioglitazone) and antioxidative agent (vitamin E), significantly improve steatosis and inflammation, they have no significant effect on liver fibrosis and have long-term safety issues. Currently, the therapeutic options for NAFLD include diet and lifestyle modification and pharmacological interventions targeting the components of MetS. Lifestyle changes, if sustained, can make significant difference in the trajectory of liver disease and overall outcomes. Finally, morbidly obese NASH patients can benefit from bariatric surgery, which may reduce liver fibrosis but carries a risk of decompensation in patients with cirrhosis.

\section{Funding}

None to declare.

\section{Conflict of interest}

The authors have no conflict of interests related to this publication.

\section{Author contributions}

Conception of the study (RK, RNP, UA), design of the study and drafting of the manuscript (RK), data collection (RK, RNP, $U A)$, manuscript revision (RNP).

\section{References}

[1] Puri P, Sanyal AJ. Nonalcoholic fatty liver disease: Definitions, risk factors, and workup. Clin Liver Dis (Hoboken) 2012;1:99-103. doi: 10.1002/cld.81.

[2] Loomba R, Sanyal AJ. The global NAFLD epidemic. Nat Rev Gastroenterol Hepatol 2013;10:686-690. doi: 10.1038/nrgastro.2013.171.

[3] Vernon G, Baranova A, Younossi ZM. Systematic review: the epidemiology and natural history of non-alcoholic fatty liver disease and non-alcoholic steatohepatitis in adults. Aliment Pharmacol Ther 2011;34:274-285. doi: 10.1111/j.1365-2036.2011.04724.x.

[4] Farrell GC, Wong VW, Chitturi S. NAFLD in Asia-as common and important as in the West. Nat Rev Gastroenterol Hepatol 2013;10:307-318. doi: 10. 1038/nrgastro.2013.34.

[5] Younossi ZM, Koenig AB, Abdelatif D, Fazel Y, Henry L, Wymer M. Global epidemiology of nonalcoholic fatty liver disease-Meta-analytic assessment of prevalence, incidence, and outcomes. Hepatology 2016;64:73-84. doi: 10.1002/hep. 28431. 
[6] Li Z, Xue J, Chen P, Chen L, Yan S, Liu L. Prevalence of nonalcoholic fatty liver disease in mainland of China: a meta-analysis of published studies. J Gastroenterol Hepatol 2014;29:42-51. doi: 10.1111/jgh.12428.

[7] Kojima S, Watanabe N, Numata M, Ogawa T, Matsuzaki S. Increase in the prevalence of fatty liver in Japan over the past 12 years: analysis of clinical background. J Gastroenterol 2003;38:954-961. doi: 10.1007/s00535-0031178-8.

[8] Kim D, Touros A, Kim WR. Nonalcoholic fatty liver disease and metabolic syndrome. Clin Liver Dis 2018;22:133-140. doi: 10.1016/j.cld.2017.08. 010 .

[9] Kumar R. Hard clinical outcomes in patients with NAFLD. Hepatol Int 2013;7 Suppl 2:790-799. doi: 10.1007/s12072-013-9455-y.

[10] VanWagner LB, Rinella ME. Extrahepatic manifestations of nonalcoholic fatty liver disease. Curr Hepatol Rep 2016;15:75-85. doi: 10 1007/s11901-016-0295-9.

[11] Xu C, Qiao Z, Lu Y, Zhang D, Jia Z, Zhuang X, et al. Influence of fatty liver on the severity and clinical outcome in acute pancreatitis. PLoS One $2015 ; 10$ : e0142278. doi: 10.1371/journal.pone.0142278.

[12] $\mathrm{Hu} J, \mathrm{Xu} Y, \mathrm{He} Z$, Zhang $\mathrm{H}$, Lian $\mathrm{X}$, Zhu $\mathrm{T}$, et al. Increased risk of cerebrovascular accident related to non-alcoholic fatty liver disease: a meta-analysis. Oncotarget 2017;9:2752-2760. doi: 10.18632/oncotarget.22755.

[13] Sun Y, Dai W, Liang Y, Yang P, Yang Q, Liang M, et al. Relationship between nonalcoholic fatty liver disease and bone mineral density in adolescents with obesity: a meta-analysis. Diabetes Metab Syndr Obes 2019;12:199207. doi: 10.2147/DMSO.S192256.

[14] Wong RJ, Cheung R, Ahmed A. Nonalcoholic steatohepatitis is the most rapidly growing indication for liver transplantation in patients with hepatocellular carcinoma in the U.S. Hepatology 2014;59:2188-2195. doi: 10. 1002/hep. 26986

[15] Wong RJ, Aguilar M, Cheung R, Perumpail RB, Harrison SA, Younossi ZM, et al. Nonalcoholic steatohepatitis is the second leading etiology of liver disease among adults awaiting liver transplantation in the United States. Gastroenterology 2015;148:547-555. doi: 10.1053/j.gastro.2014.11.039.

[16] Younossi ZM, Stepanova M, Afendy $M$, Fang $Y$, Younossi $Y$, Mir $H$, et al. Changes in the prevalence of the most common causes of chronic liver diseases in the United States from 1988 to 2008. Clin Gastroenterol Hepatol 2011;9:524-530.e1. doi: 10.1016/j.cgh.2011.03.020.

[17] Chalmers J, Ban L, Leena KB, Edwards KL, Grove JL, Aithal GP, et al. Cohort profile: the Trivandrum non-alcoholic fatty liver disease (NAFLD) cohort. BMJ Open 2019;9:e027244. doi: 10.1136/bmjopen-2018-027244.

[18] Estes C, Razavi H, Loomba R, Younossi Z, Sanyal AJ. Modeling the epidemic of nonalcoholic fatty liver disease demonstrates an exponential increase in burden of disease. Hepatology 2018;67:123-133. doi: 10.1002/hep. 29466.

[19] Divella R, Mazzocca A, Daniele A, Sabbà C, Paradiso A. Obesity, nonalcoholic fatty liver disease and adipocytokines network in promotion of cancer. Int Biol Sci 2019;15:610-616. doi: 10.7150/ijbs.29599.

[20] Dai W, Ye L, Liu A, Wen SW, Deng J, Wu X, et al. Prevalence of nonalcoholic fatty liver disease in patients with type 2 diabetes mellitus: A meta-analysis. Medicine (Baltimore) 2017;96:e8179. doi: 10.1097/MD. 0000000000008179 .

[21] Li L, Liu DW, Yan HY, Wang ZY, Zhao SH, Wang B. Obesity is an independent risk factor for non-alcoholic fatty liver disease: evidence from a meta-analysis of 21 cohort studies. Obes Rev 2016;17:510-519. doi: 10.1111/obr. 12407.

[22] Polyzos SA, Kountouras J, Mantzoros CS. Obesity and nonalcoholic fatty liver disease: From pathophysiology to therapeutics. Metabolism 2019; 92:82-97. doi: 10.1016/j.metabol.2018.11.014.

[23] Hazlehurst JM, Woods C, Marjot T, Cobbold JF, Tomlinson JW. Non-alcoholic fatty liver disease and diabetes. Metabolism 2016;65:1096-1108. doi: 10 1016/j.metabol.2016.01.001.

[24] Kumar R, Mohan S. Non-alcoholic fatty liver disease in lean subjects: Characteristics and implications. J Clin Transl Hepatol 2017;5:216-223. doi: 10. 14218/JCTH.2016.00068.

[25] Sookoian S, Pirola CJ. Genetic predisposition in nonalcoholic fatty liver disease. Clin Mol Hepatol 2017;23:1-12. doi: 10.3350/cmh.2016.0109.

[26] Teli MR, James OF, Burt AD, Bennett MK, Day CP. The natural history of nonalcoholic fatty liver: a follow-up study. Hepatology 1995;22:17141719. doi: 10.1002/hep.1840220616.

[27] Wong VW, Wong GL, Choi PC, Chan AW, Li MK, Chan HY, et al. Disease progression of non-alcoholic fatty liver disease: a prospective study with paired liver biopsies at 3 years. Gut 2010;59:969-974. doi: 10.1136/gut. 2009.205088.

[28] MCPherson S, Hardy T, Henderson E, Burt AD, Day CP, Anstee QM. Evidence of NAFLD progression from steatosis to fibrosing-steatohepatitis using paired biopsies: implications for prognosis and clinical management. J Hepatol 2015;62:1148-1155. doi: 10.1016/j.jhep.2014.11.034.

[29] Singh S, Allen AM, Wang Z, Prokop LJ, Murad MH, Loomba R. Fibrosis progression in nonalcoholic fatty liver vs nonalcoholic steatohepatitis: a systematic review and meta-analysis of paired-biopsy studies. Clin
Gastroenterol Hepatol 2015;13:643-654.e9. doi: 10.1016/j.cgh.2014.04. 014.

[30] Argo CK, Northup PG, Al-Osaimi AM, Caldwell SH. Systematic review of risk factors for fibrosis progression in non-alcoholic steatohepatitis. J Hepatol 2009;51:371-379. doi: 10.1016/j.jhep.2009.03.019.

[31] Harrison SA, Torgerson S, Hayashi PH. The natural history of nonalcoholic fatty liver disease: a clinical histopathological study. Am J Gastroenterol 2003;98:2042-2047. doi: 10.1111/j.1572-0241.2003.07659.x.

[32] Sorrentino P, Tarantino G, Conca P, Perrella A, Terracciano ML, Vecchione R, et al. Silent non-alcoholic fatty liver disease-a clinical-histological study. J Hepatol 2004;41:751-757. doi: 10.1016/j.jhep.2004.07.010.

[33] Boursier J, Fraysse J, Lafuma A, Fabron C, Sanatan S. THU-299-Increased risk of mortality with liver disease progression in non-alcoholic fatty liver disease/non-alcoholic steatohepatitis patients: An analysis of French national hospital care. J Hepatol 2019;70:e291-e292. doi: 10. 1016/S0618-8278(19)30562-6.

[34] Powell EE, Cooksley WG, Hanson R, Searle J, Halliday JW, Powell LW. The natural history of nonalcoholic steatohepatitis: a follow-up study of fortytwo patients for up to 21 years. Hepatology 1990;11:74-80. doi: 10. 1002/hep.1840110114.

[35] Ayata G, Gordon FD, Lewis WD, Pomfret E, Pomposelli JJ, Jenkins RL, et al. Cryptogenic cirrhosis: clinicopathologic findings at and after liver transplantation. Hum Pathol 2002:33:1098-1104. doi: 10.1053/hupa 2002.129419.

[36] Nayak NC, Jain D, Vasdev N, Gulwani H, Saigal S, Soin A. Etiologic types of end-stage chronic liver disease in adults: analysis of prevalence and their temporal changes from a study on native liver explants. Eur ] Gastroenterol Hepatol 2012;24:1199-1208. doi: 10.1097/MEG.0b013e32835643f1.

[37] Bugianesi E, Leone N, Vanni E, Marchesini G, Brunello F, Carucci P, et al. Expanding the natural history of nonalcoholic steatohepatitis: from cryptogenic cirrhosis to hepatocellular carcinoma. Gastroenterology 2002;123: 134-140. doi: 10.1053/gast.2002.34168.

[38] Jepsen P, Vilstrup H, Mellemkjaer L, Thulstrup AM, Olsen JH, Baron JA, et al. Prognosis of patients with a diagnosis of fatty liver-a registry-based cohort study. Hepatogastroenterology 2003;50:2101-2104.

[39] Nayak NC, Vasdev N, Saigal S, Soin AS. End-stage nonalcoholic fatty liver disease: evaluation of pathomorphologic features and relationship to cryptogenic cirrhosis from study of explant livers in a living donor liver transplant program. Hum Pathol 2010;41:425-430. doi: 10.1016/j.humpath 2009.06.021.

[40] Said A, Ghufran A. Epidemic of non-alcoholic fatty liver disease and hepatocellular carcinoma. World J Clin Oncol 2017;8:429-436. doi: 10 5306/wjco.v8.i6.429.

[41] Paradis V, Zalinski S, Chelbi E, Guedj N, Degos F, Vilgrain V, et al. Hepatocellular carcinomas in patients with metabolic syndrome often develop without significant liver fibrosis: a pathological analysis. Hepatology 2009;49:851-859. doi: 10.1002/hep.22734.

[42] Piscaglia F, Svegliati-Baroni G, Barchetti A, Pecorelli A, Marinelli S, Tiribelli $C$, et al. Clinical patterns of hepatocellular carcinoma in nonalcoholic fatty liver disease: A multicenter prospective study. Hepatology 2016;63:827838. doi: $10.1002 /$ hep. 28368 .

[43] Kawada N, Imanaka K, Kawaguchi T, Tamai C, Ishihara R, Matsunaga T, et al. Hepatocellular carcinoma arising from non-cirrhotic nonalcoholic steatohepatitis. J Gastroenterol 2009;44:1190-1194. doi: 10.1007/s00535009-0112-0.

[44] Takuma Y, Nouso K. Nonalcoholic steatohepatitis-associated hepatocellular carcinoma: our case series and literature review. World J Gastroenterol 2010;16:1436-1441. doi: 10.3748/wjg.v16.i12.1436.

[45] Younossi ZM, Otgonsuren M, Henry L, Venkatesan C, Mishra A, Erario M, et al. Association of nonalcoholic fatty liver disease (NAFLD) with hepatocellular carcinoma (HCC) in the United States from 2004 to 2009. Hepatology 2015;62:1723-1730. doi: 10.1002/hep.28123.

[46] Dyson J, Jaques B, Chattopadyhay D, Lochan R, Graham J, Das D, et al. Hepatocellular cancer: the impact of obesity, type 2 diabetes and a multidisciplinary team. J Hepatol 2014;60:110-117. doi: 10.1016/j.jhep.2013. 08.011.

[47] Cho EJ, Kwack MS, Jang ES, You SJ, Lee JH, Kim YJ, et al. Relative etiological role of prior hepatitis $B$ virus infection and nonalcoholic fatty liver disease in the development of non-B non-C hepatocellular carcinoma in a hepatitis B-endemic area. Digestion 2011;84 Suppl 1:17-22. doi: 10.1159/000333210.

[48] Wong SW, Ting YW, Chan WK. Epidemiology of non-alcoholic fatty liver disease-related hepatocellular carcinoma and its implications. JGH Open 2018;2:235-241. doi: 10.1002/jgh3.12070.

[49] Weinmann A, Alt Y, Koch S, Nelles C, Düber C, Lang H, et al. Treatment and survival of non-alcoholic steatohepatitis associated hepatocellular carcinoma. BMC Cancer 2015;15:210. doi: 10.1186/s12885-015-1197-x.

[50] Angulo P, Kleiner DE, Dam-Larsen S, Adams LA, Bjornsson ES, Charatcharoenwitthaya $P$, et al. Liver fibrosis, but no other histologic features, is associated with long-term outcomes of patients with nonalcoholic fatty liver disease. Gastroenterology 2015;149:389-397.e10. doi: 10.1053/j. gastro.2015.04.043. 
[51] Ong JP, Pitts A, Younossi ZM. Increased overall mortality and liver-related mortality in non-alcoholic fatty liver disease. J Hepatol 2008;49:608-612. doi: $10.1016 / j$.jhep.2008.06.018.

[52] Söderberg C, Stål P, Askling J, Glaumann H, Lindberg G, Marmur J, et al. Decreased survival of subjects with elevated liver function tests during a 28-year follow-up. Hepatology 2010;51:595-602. doi: 10.1002/hep. 23314.

[53] Ekstedt M, Hagström H, Nasr P, Fredrikson M, Stål P, Kechagias $S$, et al. Fibrosis stage is the strongest predictor for disease-specific mortality in NAFLD after up to 33 years of follow-up. Hepatology 2015;61:15471554. doi: $10.1002 /$ hep. 27368 .

[54] Musso G, Gambino R, Cassader M, Pagano G. Meta-analysis: natural history of non-alcoholic fatty liver disease (NAFLD) and diagnostic accuracy of noninvasive tests for liver disease severity. Ann Med 2011;43:617-649. doi: 10.3109/07853890.2010.518623.

[55] Zhou YJ, Li YY, Nie YQ, Huang CM, Cao CY. Natural course of nonalcoholic fatty liver disease in southern China: a prospective cohort study. J Dig Dis 2012;13:153-160. doi: 10.1111/j.1751-2980.2011.00571.x.

[56] Kim D, Kim WR, Kim HJ, Therneau TM. Association between noninvasive fibrosis markers and mortality among adults with nonalcoholic fatty liver disease in the United States. Hepatology 2013;57:1357-1365. doi: 10. 1002/hep. 26156

[57] Dulai PS, Singh S, Patel J, Soni M, Prokop LJ, Younossi Z, et al. Increased risk of mortality by fibrosis stage in nonalcoholic fatty liver disease: Systematic review and meta-analysis. Hepatology 2017;65:1557-1565. doi: 10.1002/hep. 29085

[58] Ekstedt M, Franzén LE, Mathiesen UL, Thorelius L, Holmqvist M, Bodemar G et al. Long-term follow-up of patients with NAFLD and elevated liver enzymes. Hepatology 2006;44:865-873. doi: 10.1002/hep.21327.

[59] Fraser A, Harris R, Sattar N, Ebrahim S, Davey Smith G, et al. Alanine aminotransferase, gamma-glutamyltransferase, and incident diabetes: the British Women's Heart and Health Study and meta-analysis. Diabetes Care 2009;32:741-750. doi: 10.2337/dc08-1870.

[60] Younossi ZM, Stepanova M, Rafiq N, Makhlouf H, Younoszai Z, Agrawal R, et al. Pathologic criteria for nonalcoholic steatohepatitis: interprotocol agreement and ability to predict liver-related mortality. Hepatology 2011; 53:1874-1882. doi: 10.1002/hep.24268.

[61] Targher G, Lonardo A, Byrne CD. Nonalcoholic fatty liver disease and chronic vascular complications of diabetes mellitus. Nat Rev Endocrinol 2018;14: 99-114. doi: 10.1038/nrendo.2017.173.

[62] Pugh CJ, Spring VS, Kemp GJ, Richardson P, Shojaee-Moradie F, Umpleby $\mathrm{AM}$, et al. Exercise training reverses endothelial dysfunction in nonalcoholic fatty liver disease. Am J Physiol Heart Circ Physiol 2014;307:H1298H1306. doi: 10.1152/ajpheart.00306.2014.

[63] Kim HC, Kim DJ, Huh KB. Association between nonalcoholic fatty liver disease and carotid intima-media thickness according to the presence of metabolic syndrome. Atherosclerosis 2009;204:521-525. doi: 10.1016/j. atherosclerosis.2008.09.012.

[64] Lee YJ, Shim JY, Moon BS, Shin YH, Jung DH, Lee JH, et al. The relationship between arterial stiffness and nonalcoholic fatty liver disease. Dig Dis Sci 2012;57:196-203. doi: 10.1007/s10620-011-1819-3.

[65] Kim D, Choi SY, Park EH, Lee W, Kang JH, Kim W, et al. Nonalcoholic fatty liver disease is associated with coronary artery calcification. Hepatology 2012;56:605-613. doi: 10.1002/hep.25593.

[66] Sookoian S, Pirola C]. Non-alcoholic fatty liver disease is strongly associated with carotid atherosclerosis: a systematic review. J Hepatol 2008;49: 600-607. doi: 10.1016/j.jhep.2008.06.012

[67] Oni ET, Agatston AS, Blaha MJ, Fialkow J, Cury R, Sposito A, et al. A systematic review: burden and severity of subclinical cardiovascular disease among those with nonalcoholic fatty liver; should we care? Atherosclerosis 2013;230:258-267. doi: 10.1016/j.atherosclerosis.2013.07.052.

[68] Sinn DH, Cho SJ, Gu S, Seong D, Kang D, Kim H, et al. Persistent nonalcoholic fatty liver disease increases risk for carotid atherosclerosis. Gastroenterology 2016;151:481-488.e1. doi: 10.1053/j.gastro.2016.06.001.

[69] Sahebkar A, Chew GT, Watts GF. New peroxisome proliferator-activated receptor agonists: potential treatments for atherogenic dyslipidemia and non-alcoholic fatty liver disease. Expert Opin Pharmacother 2014;15: 493-503. doi: 10.1517/14656566.2014.876992.

[70] Karabay CY, Kocabay G, Kalayci A, Colak Y, Oduncu V, Akgun T, et al. Impaired left ventricular mechanics in nonalcoholic fatty liver disease: a speckle-tracking echocardiography study. Eur J Gastroenterol Hepatol 2014;26:325-331. doi: 10.1097/MEG.0000000000000008.

[71] Fotbolcu H, Yakar T, Duman D, Karaahmet T, Tigen K, Cevik C, et al. Impairment of the left ventricular systolic and diastolic function in patients with non-alcoholic fatty liver disease. Cardiol J 2010;17:457-463. doi: 10. 1097/mbp.0b013e328339e2c8.

[72] Käräjämäki AJ, Pätsi OP, Savolainen M, Kesäniemi YA, Huikuri H, Ukkola O Non-alcoholic fatty liver disease as a predictor of atrial fibrillation in middleaged population (OPERA study). PLoS One 2015;10:e0142937. doi: 10. 1371/journal.pone.0142937.
[73] Hung CS, Tseng PH, Tu CH, Chen CC, Liao WC, Lee YC, et al. Nonalcoholic fatty liver disease is associated with QT prolongation in the general population. J Am Heart Assoc 2015;4:e001820. doi: 10.1161/JAHA.115. 001820.

[74] Robbins J, Nelson JC, Rautaharju PM, Gottdiener JS. The association between the length of the QT interval and mortality in the Cardiovascular Health Study. Am J Med 2003;115:689-694. doi: 10.1016/j.amjmed.2003. 07.014.

[75] Verrijken A, Francque S, Mertens I, Prawitt J, Caron S, Hubens G, et al. Prothrombotic factors in histologically proven nonalcoholic fatty liver disease and nonalcoholic steatohepatitis. Hepatology 2014;59:121-129. doi: 10.1002/hep. 26510.

[76] Wong VW, Wong GL, Yeung JC, Fung CY, Chan JK, Chang ZH, et al. Longterm clinical outcomes after fatty liver screening in patients undergoing coronary angiogram: A prospective cohort study. Hepatology 2016;63: 754-763. doi: 10.1002/hep.28253.

[77] Wu S, Wu F, Ding Y, Hou J, Bi J, Zhang Z. Association of non-alcoholic fatty liver disease with major adverse cardiovascular events: A systematic review and meta-analysis. Sci Rep 2016;6:33386. doi: 10.1038/srep33386.

[78] Targher G, Byrne CD, Lonardo A, Zoppini G, Barbui C. Non-alcoholic fatty liver disease and risk of incident cardiovascular disease: A meta-analysis. J Hepatol 2016;65:589-600. doi: 10.1016/j.jhep.2016.05.013.

[79] Allen AM, Hicks SB, Mara KC, Larson JJ, Therneau TM. The risk of incident extrahepatic cancers is higher in non-alcoholic fatty liver disease than obesity - A longitudinal cohort study. J Hepatol 2019;71:1229-1236. doi: 10.1016/j.jhep.2019.08.018.

[80] Lee YI, Lim YS, Park HS. Colorectal neoplasms in relation to non-alcoholic fatty liver disease in Korean women: a retrospective cohort study. J Gastroenterol Hepatol 2012;27:91-95. doi: 10.1111/j.1440-1746.2011.06816.x.

[81] Wong VW, Wong GL, Tsang SW, Fan T, Chu WC, Woo J, et al. High prevalence of colorectal neoplasm in patients with non-alcoholic steatohepatitis. Gut 2011;60:829-836. doi: 10.1136/gut.2011.237974.

[82] Huang KW, Leu HB, Wang Y], Luo JC, Lin HC, Lee FY, et al. Patients with nonalcoholic fatty liver disease have higher risk of colorectal adenoma after negative baseline colonoscopy. Colorectal Dis 2013;15:830-835. doi: 10. $1111 /$ codi.12172

[83] Bilici A, Ozguroglu M, Mihmanli I, Turna H, Adaletli I. A case-control study of non-alcoholic fatty liver disease in breast cancer. Med Oncol 2007;24:367371. doi: 10.1007/s12032-007-0034-8.

[84] Musso G, Gambino R, Tabibian JH, Ekstedt M, Kechagias S, Hamaguchi M, et al. Association of non-alcoholic fatty liver disease with chronic kidney disease: a systematic review and meta-analysis. PLoS Med 2014;11: e1001680. doi: 10.1371/journal.pmed.1001680.

[85] Targher G, Chonchol MB, Byrne CD. CKD and nonalcoholic fatty liver disease. Am J Kidney Dis 2014;64:638-652. doi: 10.1053/j.ajkd.2014. 05.019 .

[86] Singal AK, Salameh $H$, Kuo YF, Wiesner RH. Evolving frequency and outcomes of simultaneous liver kidney transplants based on liver disease etiology. Transplantation 2014;98:216-221. doi: 10.1097/TP.0000000000000048.

[87] Musso G, Cassader M, Cohney S, Pinach S, Saba F, Gambino R. Emerging liver-kidney interactions in nonalcoholic fatty liver disease. Trends Mol Med 2015;21:645-662. doi: 10.1016/j.molmed.2015.08.005.

[88] Targher G, Rossini M, Lonardo A. Evidence that non-alcoholic fatty liver disease and polycystic ovary syndrome are associated by necessity rather than chance: a novel hepato-ovarian axis? Endocrine 2016;51:211-221. doi: 10.1007/s12020-015-0640-8.

[89] Rocha ALL, Faria LC, Guimarães TCM, Moreira GV, Cândido AL, Couto CA, et al. Non-alcoholic fatty liver disease in women with polycystic ovary syndrome: systematic review and meta-analysis. J Endocrinol Invest 2017;40: 1279-1288. doi: 10.1007/s40618-017-0708-9.

[90] Kelley CE, Brown AJ, Diehl AM, Setji TL. Review of nonalcoholic fatty liver disease in women with polycystic ovary syndrome. World J Gastroenterol 2014;20:14172-14184. doi: 10.3748/wjg.v20.i39.14172.

[91] Heinzer R, Vat S, Marques-Vidal P, Marti-Soler H, Andries D, Tobback N, et al. Prevalence of sleep-disordered breathing in the general population: the HypnoLaus study. Lancet Respir Med 2015;3:310-318. doi: 10. 1016/S2213-2600(15)00043-0.

[92] Mesarwi OA, Loomba R, Malhotra A. Obstructive sleep apnea, hypoxia, and nonalcoholic fatty liver disease. Am J Respir Crit Care Med 2019;199:830841. doi: 10.1164/rccm.201806-1109TR.

[93] Aron-Wisnewsky J, Minville C, Tordjman J, Lévy P, Bouillot JL, Basdevant A, et al. Chronic intermittent hypoxia is a major trigger for non-alcoholic fatty liver disease in morbid obese. J Hepatol 2012;56:225-233. doi: 10.1016/j. jhep.2011.04.022.

[94] Minville C, Hilleret MN, Tamisier R, Aron-Wisnewsky J, Clement K, Trocme C, et al. Nonalcoholic fatty liver disease, nocturnal hypoxia, and endothelial function in patients with sleep apnea. Chest 2014;145:525-533. doi: 10 . 1378/chest.13-0938.

[95] van der Voort EA, Koehler EM, Dowlatshahi EA, Hofman A, Stricker BH, Janssen $\mathrm{HL}$, et al. Psoriasis is independently associated with nonalcoholic 
fatty liver disease in patients 55 years old or older: Results from a population-based study. J Am Acad Dermatol 2014;70:517-524. doi: 10.1016/j. jaad.2013.10.044.

[96] Miele L, Vallone S, Cefalo C, La Torre G, Di Stasi C, Vecchio FM, et al. Prevalence, characteristics and severity of non-alcoholic fatty liver disease in patients with chronic plaque psoriasis. J Hepatol 2009;51:778-786. doi: 10.1016/j.jhep.2009.06.008.

[97] Gisondi P, Targher G, Zoppini G, Girolomoni G. Non-alcoholic fatty liver disease in patients with chronic plaque psoriasis. J Hepatol 2009;51:758764. doi: $10.1016 /$ j.jhep.2009.04.020.

[98] Targher G, Lonardo A, Rossini M. Nonalcoholic fatty liver disease and decreased bone mineral density: is there a link? J Endocrinol Invest 2015; 38:817-825. doi: 10.1007/s40618-015-0315-6.

[99] Li M, Xu Y, Xu M, Ma L, Wang T, Liu Y, et al. Association between nonalcoholic fatty liver disease (NAFLD) and osteoporotic fracture in middle-aged and elderly Chinese. J Clin Endocrinol Metab 2012;97:2033-2038. doi: 10. 1210/jc.2011-3010.

[100] Koo BK, Kim D, Joo SK, Kim JH, Chang MS, Kim BG, et al. Sarcopenia is an independent risk factor for non-alcoholic steatohepatitis and significant fibrosis. J Hepatol 2017;66:123-131. doi: 10.1016/j.jhep.2016.08.019.

[101] Kim G, Lee SE, Lee YB, Jun JE, Ahn J, Bae JC, et al. Relationship between relative skeletal muscle mass and nonalcoholic fatty liver disease: A 7-year longitudinal study. Hepatology 2018;68:1755-1768. doi: 10.1002/hep. 30049.

[102] Mahfood Haddad T, Hamdeh S, Kanmanthareddy A, Alla VM. Nonalcoholic fatty liver disease and the risk of clinical cardiovascular events: A systematic review and meta-analysis. Diabetes Metab Syndr 2017;11 Suppl 1: S209-S216. doi: 10.1016/j.dsx.2016.12.033.

[103] Ray S, Mehta NN, Golhar A, Nundy S. Post hepatectomy liver failure - A comprehensive review of current concepts and controversies. Ann Med Surg (Lond) 2018;34:4-10. doi: 10.1016/j.amsu.2018.08.012.

[104] Behrns KE, Tsiotos GG, DeSouza NF, Krishna MK, Ludwig J, Nagorney DM. Hepatic steatosis as a potential risk factor for major hepatic resection. J Gastrointest Surg 1998;2:292-298. doi: 10.1016/s1091-255x(98) 80025-5.

[105] Belghiti ], Hiramatsu K, Benoist S, Massault P, Sauvanet A, Farges O. Seven hundred forty-seven hepatectomies in the 1990s: an update to evaluate the actual risk of liver resection. J Am Coll Surg 2000;191:38-46. doi: 10.1016/s1072-7515(00)00261-1.

[106] Vauthey JN, Pawlik TM, Ribero D, Wu TT, Zorzi D, Hoff PM, et al. Chemotherapy regimen predicts steatohepatitis and an increase in 90-day mortality after surgery for hepatic colorectal metastases. J Clin Oncol 2006;24: 2065-2072. doi: 10.1200/JCO.2005.05.3074.

[107] Linares I, Hamar M, Selzner N, Selzner M. Steatosis in liver transplantation: Current limitations and future strategies. Transplantation 2019;103:7890. doi: 10.1097/TP.0000000000002466.

[108] Marsman WA, Wiesner RH, Rodriguez L, Batts KP, Porayko MK, Hay JE, et al. Use of fatty donor liver is associated with diminished early patient and graft survival. Transplantation 1996;62:1246-1251. doi: 10.1097/00007890199611150-00011.

[109] Malik SM, Devera ME, Fontes P, Shaikh O, Sasatomi E, Ahmad J. Recurrent disease following liver transplantation for nonalcoholic steatohepatitis cirrhosis. Liver Transpl 2009;15:1843-1851. doi: 10.1002/It.21943.
[110] Yalamanchili K, Saadeh S, Klintmalm GB, Jennings LW, Davis GL. Nonalcoholic fatty liver disease after liver transplantation for cryptogenic cirrhosis or nonalcoholic fatty liver disease. Liver Transpl 2010;16:431-439. doi: 10. $1002 /$ It. 22004.

[111] Caballería L, Pera G, Auladell MA, Torán P, Muñoz L, Miranda D, et al. Prevalence and factors associated with the presence of nonalcoholic fatty liver disease in an adult population in Spain. Eur J Gastroenterol Hepatol 2010; 22:24-32. doi: 10.1097/MEG.0b013e32832fcdfo.

[112] Suomela E, Oikonen M, Virtanen J, Parkkola R, Jokinen E, Laitinen T, et al. Prevalence and determinants of fatty liver in normal-weight and overweight young adults. The Cardiovascular Risk in Young Finns Study. Ann Med 2015; 47:40-46. doi: 10.3109/07853890.2014.966752.

[113] Ruhl CE, Everhart JE. Relationship of non-alcoholic fatty liver disease with cholecystectomy in the US population. Am J Gastroenterol 2013;108:952958. doi: 10.1038/ajg.2013.70.

[114] Shen HC, Zhao ZH, Hu YC, Chen YF, Tung TH. Relationship between obesity, metabolic syndrome, and nonalcoholic fatty liver disease in the elderly agricultural and fishing population of Taiwan. Clin Interv Aging 2014;9:501508. doi: 10.2147/CIA.S59538.

[115] Younossi ZM, Otgonsuren M, Venkatesan C, Mishra A. In patients with nonalcoholic fatty liver disease, metabolically abnormal individuals are at higher risk for mortality while metabolically normal individuals are not. Metabolism 2013;62:352-360. doi: 10.1016/j.metabol.2012.08.005.

[116] Chang Y, Jung HS, Yun KE, Cho J, Cho YK, Ryu S. Cohort study of nonalcoholic fatty liver disease, NAFLD fibrosis score, and the risk of incident diabetes in a Korean population. Am J Gastroenterol 2013;108:18611868. doi: 10.1038 /ajg.2013.349.

[117] Cai W, Wu X, Zhang B, Miao L, Sun YP, Zou Y, et al. Serum uric acid levels and non-alcoholic fatty liver disease in Uyghur and Han ethnic groups in northwestern China. Arq Bras Endocrinol Metabol 2013;57:617-622. doi: 10.1590/s0004-27302013000800006.

[118] Dassanayake AS, Kasturiratne A, Rajindrajith S, Kalubowila U, Chakrawarthi $\mathrm{S}$, De Silva AP, et al. Prevalence and risk factors for non-alcoholic fatty liver disease among adults in an urban Sri Lankan population. J Gastroenterol Hepatol 2009;24:1284-1288. doi: 10.1111/j.1440-1746.2009.05831.x.

[119] Adams LA, Lymp JF, St Sauver J, Sanderson SO, Lindor KD, Feldstein A et al. The natural history of nonalcoholic fatty liver disease: a populationbased cohort study. Gastroenterology 2005;129:113-121. doi: 10.1053/j. gastro.2005.04.014.

[120] Haring R, Wallaschofski H, Nauck M, Dörr M, Baumeister SE, Völzke $H$. Ultrasonographic hepatic steatosis increases prediction of mortality risk from elevated serum gamma-glutamyl transpeptidase levels. Hepatology 2009;50:1403-1411. doi: 10.1002/hep.23135.

[121] Rafiq N, Bai C, Fang Y, Srishord M, McCullough A, Gramlich T, et al. Longterm follow-up of patients with nonalcoholic fatty liver. Clin Gastroenterol Hepatol 2009;7:234-238. doi: 10.1016/j.cgh.2008.11.005.

[122] Zeb I, Li D, Budoff MJ, Katz R, Lloyd-Jones D, Agatston A, et al. Nonalcoholic fatty liver disease and incident cardiac events: The multi-ethnic study of atherosclerosis. J Am Coll Cardiol 2016;67:1965-1966. doi: 10.1016/j. jacc.2016.01.070 